\title{
Treatments for Type 2 Diabetes; a Focus on DPP4 Inhibitors
}

\section{Gerald H Tomkin*}

Department of Diabetes and Endocrinology, Beacon Hospital and Department of Medicine, Trinity College Dublin, Ireland

\begin{abstract}
New treatments for diabetes are always exciting in the beginning but as experience grows their position in management becomes less certain. This review focuses on DPP4 inhibitors and their place in management of type 2 diabetes. Although hypoglycaemia is rarely an issue, the effectiveness in reduction in blood sugar is greatest at the higher blood sugar levels, hence much of the value of using DPP4 inhibitors rests in the target HbA1c chosen for the individual patient.
\end{abstract}

\section{Keywords: Type 2 diabetes; DPP4 inhibitors; Incretins}

\section{Introduction}

One should not forget that before the discovery of insulin 90 years ago diabetes was a rapidly fatal disease and there was little interest in what we now term type 2 diabetes. Type 2 diabetes makes up $90 \%$ of all diabetes. Insulin resistance rather than insulin deficiency is the major player in most diabetes and diabetes can be reversed at least in many patients through weight reduction by diet with or without the help of bariatric surgery $[1,2]$. Following the publication of the article by the Newcastle group, the Finnish diabetologist, Yki Yarvinen wrote in an editorial" the only problem is that in medical school and when I was training as an endocrinologist nobody told me how to get patients to follow such a diet" [3].

Stepwise approach to the management of diabetes has become a fashionable concept in recent years with many published paradigms of the steps which are variable and often contradictory or display so many different stairways that they become very confusing. The first step depends on getting the patient at the very beginning of their path, that is in the pre-diabetes stage, but even then they may have already suffered from macrovascular and/or microvascular damage [4-7]. There is little dissention in the benefit of advising lifestyle changes but should metformin also be used or should one wait and see the effect first of the lifestyle changes? Information on this point is available. For example in the trial by Snehalatha et al. [8] there seemed to be no advantage to adding metformin to life style changes so perhaps metformin should be reserved for those patients who are unable to adhere to lifestyle changes? Once diabetes has been diagnosed can one wait and see the result of life style changes or should one aggressively control blood sugar? High glucose is toxic to the B cell. Exciting new information suggests that the B cell may de-differentiate under high glucose attack by causing reduction in a key transcription, factor Fox 01. This de-differentiation results in the production of inactive proinsulin and an increase in glucagon [9]. Intensive insulin therapy at diagnosis of type 2 diabetes has been shown to reverse diabetes [10]. The authors studied 382 patients and had divided them into 3 groups. Continuous insulin, multiple injections or oral agents were used to achieve rapid normalisation of hyperglycaemia. Treatment was stopped after normoglycaemia was maintained for two weeks. After a year $51 \%$ and $44 \%$ of the insulin treated patients were in remission whereas only $26 \%$ of the patients in the oral agent group had gone into remission. The evidence to support early and aggressive treatment for type 2 diabetes has not been widely accepted. The reasons are probably due to a shortage of personnel to manage patients. In my country there is a long waiting list to be seen in a diabetic clinic and general practitioners are usually unhappy about starting insulin. The better understanding of the B cell pathology of diabetes should persuade physicians to adopt a more urgent approach to diabetes management in the future.

\section{Incretins}

It has been known for many years that intravenous glucose will not stimulate insulin secretion to the same extent as a similar glucose load given orally. It was discovered that hormones secreted from the intestine in response to a glucose load had the ability to release insulin from the pancreas. These hormones were called incretins and they are responsible for at least $50 \%$ of insulin secretion following a meal. In 1971 a peptide was isolated from the intestine which had the ability to inhibit gastric acid secretion and was therefore called gastric inhibitory polypeptide (GIP) [11]. GIP was later found to stimulate insulin secretion. What was very interesting was that GIP would only stimulate insulin secretion in the presence of high blood sugar. This finding has implications in treatment terms since drugs that only works with high blood sugar would be much less likely to cause hypoglycaemia.

Another incretin was discovered in 1985 and called glucagon-like peptide -1 (GLP-1) [12]. This hormone was also dependent on high blood sugar level for full action. Both GIP and GLP-1 act by binding to specific receptors and so release insulin. GLP-1 has another action, it inhibits gastric emptying and this has been of benefit in the treatment of diabetic patients because the feeling of satiety leads to weight reduction. Another beneficial effect of the reduction in rate of gastric emptying is delayed absorption of food, a mechanism which improves postprandial blood sugar excursions. GLP-1 also regulates apatite and food intake through the hypothalamus. Another interesting action of GLP-1 is the promotion of insulin biosynthesis as well as B cell proliferation and survival. It is not clear whether these effects can be translated to human studies. GLP-1 also enhances peripheral glucose disposal [13].

Exenatide is a GLP-1 receptor agonist. It is a 39 amino acid peptide produced in the salivary glands of the Gila monster lizard [14] it has 53\% amino acid homology with full length GLP-1 and it binds with greater affinity than GLP-1 to the GLP-I receptor in GLP-1 receptor expressing cells [15]. DPP-4 cleaves peptides and is responsible for the rapid breakdown of GLP-1. DPP-4 does not denature exenatide

*Corresponding author: Gerald H Tomkin, Department of Diabetes and Endocrinology, Beacon Hospital and Department of Medicine, Trinity College Dublin, Ireland, Tel. +00 3531 2390658; Fax : +00 3531 2721395; E-mail: gerald.tomkin@tcd.ie

Received December 17, 2013; Accepted January 24, 2014; Published January 31, 2014

Citation: Tomkin GH (2014) Treatments for Type 2 Diabetes; a Focus on DPP4 Inhibitors. Pharmaceut Reg Affairs 3: 114. doi:10.4172/2167-7689.1000114

Copyright: () 2014 Tomkin GH. This is an open-access article distributed under the terms of the Creative Commons Attribution License, which permits unrestricted use, distribution, and reproduction in any medium, provided the original author and source are credited. 
because of the slight amino acid differences and in human studies the half-life ranges from 3.3 to 4 hours [16].

Animal studies are exciting before the results are tested in humans but often disappointing after human experiments have failed to confirm the initial animal studies. Amyloid deposition in the islets has a detrimental effect on islet survival $[17,18]$. Studies suggest that GLP1 agonists can reduce plaque formation and toxicity in the brains of mice with Alzheimer's disease, a condition of amyloid deposition [19]. Prevention of amyloid deposition in the islets might become important in the treatment of type 2 diabetes. Park et al. [20] examined the GLP1 like analogue exenitide in cultured human islets and found that the drug enhanced survival and function of cultured human islets and reduced islet amyloid formation.

\section{DPP-4 inhibitors}

DPP-4 cleaves peptides and is responsible for the rapid breakdown of GLP-1. Inhibitors of DPP-4, which delay the breakdown of GLP-1 and therefore increase GLP-1 in the blood and prolong the action of GLP1 in the body, are therefore an important addition to the drugs controlling hyperglycaemia. An excellent review of the role of incretins in glucose homoeostasis and diabetes treatment, was published in 2008 [21] and for review of the incretins to treat type 2 diabetes in VanGall et al. [22].

There are 6 DPP- 4 inhibitors on the market minor variation in their chemical composition have not been translated to particular benefit although it should be noted that Vildagliptin and linagliptin are mostly excreted in pathways other than the kidney and hence dosage does not have to be reduced in moderate renal failure.

\section{Sitigliptin}

2. Linagliptin

3. Vildagliptin

4. Alogliptin

5. Saxagliptin

\section{Teneligliptin}

Vildagliptin, a DPP4 inhibitor which increases circulating GLP-1 levels, has been shown to ameliorate the deposition of amyloid beta and tau phosphorylation in a streptozotosin induced animal model of diabetes [23]. A study by Omar et al. [24] using a high fat diet induced obesity model in mice of advanced age has demonstrated that Vildagliptin confirms other rodent models of diabetes in preserving beta cell mass mainly through inducing beta cell proliferation and reducing beta cell apoptosis [24-26]. Omar et al. [24] found that Vildagliptin improved glucose secretion in response to oral glucose. Beta cell area was not significantly altered by Vildagliptin treatment in these mice but peri insulitis was prevented by Vildagliptin. Sitagliptin has also been shown to protect against amyloid associated beta cell loss but its effect was not different to that of Metformin [27].

It can be seen from the above discussion that there is considerable interest in the incretin system in order to improve diabetic control and perhaps also to improve beta-cell survival and perhaps to reverse or stabilise the beta-cell destruction that occurs in diabetes.

The binding modes of these drugs have recently been investigated [28]. Based on their binding sites the authors divided the drugs into 3 categorise, Vildagliptin and Saxagliptin, Alogliptin and Linagliptin, Sitagliptin and Tinegliptin. It is not clear whether these different binding modes have clinical relevance but may help in the development of better inhibitors in the future. Unlike GLP1 agonists the DPP4 inhibitors do not pass the blood brain barrier and have no effect on satiety, nor do they effect gastric emptying. Although the different DPP4 inhibitors have some differences including potency, half-lives and metabolism there does not seem to be any meaningful difference in their ability to lower blood sugar and this is probably why there are virtually no head to head studies (one head to head study showed no difference between saxagliptin and sitagliptin when combined with metformin. A good review of the differences has been written by Capuano et al. [29]. Most of the DPP4 inhibitors can be administered once daily but Vildagliptin needs to be given twice daily [30]. Saxagliptin is mainly metabolised by CYP3A4/5 isoforms to a major active metabolite 5-saxahydroxygliptin. It is suggested that the dosage of saxagliptin be modified if co administration with CYP3A4/5 inducers such as rafampicin or inhibitors such as ketoconazole.

GPR40 is a free fatty acid receptor that regulates glucose dependent insulin secretion. GPR40 has recently been examined and has been shown to have a synergistic effect with DPP4 inhibitor sitigliptin in mice. Perhaps an interesting new treatment for the future? [31]. Patients who have not been given the option of insulin but who are not controlled with lifestyle change and metformin face a variety of choices for add on treatment. Sulphonylureas traditionally were the next drug to be offered but are associated with weight gain, all be it very modest weight gain, hypoglycaemia risk, and eventually B cell failure with loss of diabetic control. The DPP-4 inhibitors, are becoming the first choice for the second drug after metformin. They are less likely to cause hypoglycaemia and are not associated with weight gain. A problem with them is that the maximum blood sugar lowering effect occurs with high blood sugars whereas when patients are near the goal of 6.5 or 7 the hypoglycaemic effect becomes less. In elderly and frail patients it has been suggested that blood sugar control should be individually tailored and these patients in particular may benefit most since their blood sugar goals will be rather higher.

A 2 year efficacy and safety study of linagliptin compared to glimepiride in patients inadequately controlled on metformin was reported in 2012 [32]. More than 1400 patients divided into two groups. HbAlc at the end of the study was similar in the two groups but there was less hypoglycaemia and there were significantly less cardiovascular events (1 versus 12) Hypoglycaemia is not usually a problem in the treatment of type 2 diabetes but recently has been suggested to be a therapeutic concern. Garber [33] refers to the many hospital visits caused by hypoglycaemia and suggests that minimisation of hypoglycaemia should be a goal for treatment of type 2 Diabetes. I would certainly agree. In a survey insulin accounted for $13.9 \%$ of overall admissions to hospital from adverse drug reactions and oral antidiabetic drugs $10.7 \%$ [34].

Linagliptin was added to Basal insulin in a trial of inadequately controlled Type 2 Diabetic patients over a 52 week period [35]. HbA1c came down from $8.3 \%$ to an average of $7.8 \%$. As in all studies with DPP4 inhibitors the hypoglycaemic effect was greater in the patients with the highest starting HbAlc. Thus DPP4 inhibitors are not so useful in bringing patients to target even though they all are effective in lowering blood sugar. The comparison in the above trial was with basal insulin but many patients with type 2 diabetes have no problem in keeping blood sugars stable overnight without overnight insulin injections. They need pre meal and in particular pre evening meal insulin to control pre bed blood sugar the pre-breakfast blood sugar reflecting pre bed sugar (Unless of course the patient snacks at bed time which is not so unusual!). 
Insulin glargine versus sitagliptin, another DPP-4 inhibitor was studied by Aschner et al. [36]. About 250 patients in each group were studied for more than 6 months. At the start patients were already on metformin which was continued during the study $\mathrm{HbAlc}$ was significantly lower in the Glargine group. There were more hypoglycaemic episodes and slight weight gain in the glargine group whereas there was slight weight loss in the Sitagliptin group.

Vildagliptin: A 24 week study in elderly patients was recently published [37]. The study investigated the feasibility of setting and achieving individualised targets over 24 weeks for elderly patients (over 70 years of age with Type 2 diabetes). The patients who were treated with vildagliptin achieved a $0.6 \%$ reduction in $\mathrm{HbAlc}$ from a baseline of $7.9 \%$ as compared with placebo. There were no tolerability issues as compared to placebo, hypoglycaemic events were $2.2 \%$ in the vildagliptin arm and $0.7 \%$ in the placebo arm. Another 24 week study in patients over 70 using Linagliptin was reported [38]. The patients were chosen if $\mathrm{HbAlc}$ was over $7 \%(54 \mathrm{mmol} / \mathrm{mol}$ ) and on sulphonylureas, metformin or insulin or some or all of these treatments. HbAlc reduction was $0.6 \%$ as compared to placebo. Hypoglycaemia occurred in $24 \%$ of the linagliptin group as compared to $16.5 \%$ in the placebo group . These 2 trials are useful in demonstrating that the DPP-4 inhibitors are safe and able to lower HbAlc by under $1 \%$ even if they are less effective the lower the starting HbAlc is. Individualising goal HbAlc is thought to be appropriate particularly in the frail elderly the benefit of reducing $\mathrm{HbA} 1 \mathrm{c}$ by less than $1 \%$ in this age group is uncertain [39]. There seems no doubt that in the frail elderly hypoglycaemia is a very serious threat to health $[40,41]$. Macrovascular disease/events seem to respond better to blood pressure and lipid interventions than to blood sugar lowering at least in the short term [42] but microvascular damage and in particular retinopathy prevention, particularly in patients who already have significant damage should make the Physician consider carefully the probable benefit of tighter blood sugar control. Under these circumstances one might not choose a DPP4 inhibitor since they work better in the higher blood sugar range and are less likely to result in the achievement of a HbAlc of $6.5 \%$ ( $48 \mathrm{mmol} / \mathrm{l})$.

The cardiovascular safety of diabetic drugs continues to raise concern [43]. In animal studies pre-treatment with either Vildigliptin or sitagliptin reduced ex-vivo myocardial infarction size in hearts perfused with buffer containing $11 \mathrm{mM}$ glucose but not $5 \mathrm{mM}$ glucose. This effect was abolished by both a GLP1 antagonist and a PKA antagonist [44]. Saxagliptin was examined by Scirica et al. [45]. They randomised 16,492 patients with type 2 diabetes who had a history of or who were at risk for cardiovascular events, to receive Saxagliptin or placebo and followed them for a median of 2.1 years. The HbAlc at the beginning of the study was $8.0 \%$ and at the end of the study the HbAlc in the Saxagliptin arm had decreased to $7.5 \%$ and the placebo arm to $7.8 \%$. A surprising finding was that more patients in the Saxagliptin group were hospitalised for heart failure but otherwise the cardiovascular end point results were similar between the two groups. Hospitalisation for hypoglycaemia occurred infrequently and was similar in the two groups but significantly more patients in the saxagliptin group reported at least one hypoglycaemic event. Thus this 2 year study gives little support for the use of saxagliptin in these patients.

Another large study specifically looking at cardiovascular disease in type 2 diabetic patients has been reported [46]. More than 5000 patients who had type 2 diabetes and either an acute MI or unstable angina requiring hospitalisation within the previous 15 to 90 days received allogliptin or placebo in addition to existing anti-diabetic and cardiovascular drug treatment. HbA1c at the start of the trial was $8.0 \%$ and at the end of the study had come down to $7.7 \%$ as compared to 7.97 in the placebo group. Hypoglycaemia was similar in the two groups. Again this large study makes one question the value of the addition of the DPP4 inhibitor which was associated with such a modest drop in HbAlc.

A 1 year follow up of DPP-4 inhibitors vs. sulfonylureas on top of metformin has been published recently [47]. Patients with prior metformin therapy received a dual combination of metformin with either DPP-4 inhibitor or sulfonylureas. There was no significant difference in either body weight or HbAlc. Hypoglycaemia was significantly less in the patients taking DPP4 inhibitors. These patients had significantly less transitory cerebral ischaemic attacks (TIA) whereas other cardiovascular events were of borderline significance. A systematic review and met-analysis of DPP4 inhibitors for the treatment of type 2 diabetes in a clinical setting was published in 2012 [48]. The conclusion was that DPP4 inhibitors can lower HbA1c in a similar way to sulphonylureas or pioglitizone with neutral effect on body weight. Increased cost and uncertainty about their long term safety should be considered.

\section{GLP-1 and the Heart}

Diabetes is associated with an increased risk of atherosclerosis and myocardial infarction. Endothelial dysfunction is a common finding in diabetes and is an early marker of atherosclerosis. GLP1 has been shown to improve endothelial dysfunction [49]. GLP-1 exerts a cardioprotective effect against ischaemic damage and heart failure. GLP-I receptors are found in the heart. Increases glucose uptake by the cardiac myocyte is beneficial in protecting the heart from ischaemia changes [50].

Studies in situ and ex-vivo suggest a beneficial effect of GLP-1 on the heart muscle when under ischaemic stress [51-54]. DPP-4 inhibitors have been less well studied in cardiac ischaemic pre-conditioning. A study by Rahmi [55] found that rapaglinide, a sulphonylurea-like drug inhibited ischaemic preconditioning as measured by stress testing in patients with Type 2 diabetes who already had evidence of coronary atherosclerosis. Vildagliptin, a DPP4 inhibitor, on the other hand, did not alter preconditioning in $72 \%$ of patients.

Atherosclerosis is an inflammatory condition. Soluble DPP-4 has been demonstrated to increase splenic CD4 positive lymphocyte migration in vitro, an effect that was abolished by sitagliptin, a finding that might have implications for the inflammatory atherosclerotic plaque [56]. GLP-1 may also reduce monocyte adhesion to the vessel wall [57] but whether DPP4 inhibitor will be effective in reducing the burden of atherosclerosis has yet to be shown. Sitigliptin and NVPDPP728 another DPP4 inhibitor have been shown to markedly reduce foam cell formation. The study showed that the repression of foam cell formation was through the inhibition of the scavenger receptors CD36 and Lox 1 most likely through the inhibition of PKC activity [58]. An excellent review of cardiovascular effects of GLP1 and GLP-1 based therapies has been published by Burgmaier et al. [59]. Sitagliptin has been shown to decrease triglycerides and free fatty acids and increase HDL cholesterol in patients with Type 2 diabetes but this was only in a 12 week study [60]. Vildagliptin has been shown to reduce postprandial intestinal triglyceride particles [61]. Both the study by Nordestgaard [62] and Zaruba et al. [63] suggested that the tryglyceride-rich particles are associated with risk of myocardial infarction. Thus the finding of reduced triglycerides with sitagliptin may be a reason to hope that the DPP4 inhibitors would protect the heart, the chemokine SDF-1 is a substrate for DPP-4. The receptor for SDF-1(CXCR-4) is found on stem cells [61]. Zaruba et al. [63] examined whether inhibition of DPP4 with sitagliptin might raise SDF1 levels 
and increase the homing of stem cells to the injured myocardium in an animal model of myocardial infarction. They showed that re-modelling was induced and heart function and survival improved. There is now a trial under way in humans to assess the clinical relevance of these findings (The sitagliptin plus granulocyte stimulating Factor in patient's suffering from acute myocardial infarction) [64].

Matsubara et al. examined 44 patients with coronary artery disease and uncontrolled diabetes (HbA1c >7.4\%) [65]. Sitagliptin or aggressive conventional treatment was compared after 6 months. Endothelial function was significantly improved in the sitagliptin group with no difference in fasting blood sugar at the end of the trial but a reduction in $\mathrm{HbAlc}$ of $0.6 \%$ in each group. C-reactive protein (CRP) reduced significantly in the sitagliptin group with a significant correlation between the CRP and the vascular reactivity but not with HbAlc.

In animal experiments it has been shown that DPP4 inhibition reduces albuminurea and ameliorated diabetic nephropathy independent of the glucose lowering effect $[66,67]$. A recent study has shown that alogliptin seemed better than sitigliptin in reducing urinary levels of albumin and an oxidative stress marker. This was associated with an elevated level of stromal cell derived factor 1a (SDF-1a). It will be interesting to see whether this finding will be translated to renal protection in long term studies [68].

There has been much discussion about HbAlc targets in recent years due to the uncertainty of what constitutes a safe blood sugar level. This is not surprising as a raised blood sugar is not a pathological disease but rather a marker of a metabolic disorder caused by a failure of the beta cell to produce enough insulin. Insulin resistance adds another dimension so that the insulin deficiency may be relative rather than absolute. The next problem is that, although many studies have shown beyond doubt that there is a direct correlation between the blood sugar or HbAlc level and complications of diabetes, both macro and micro vascular, it has been more difficult to show a lessening of risk of macrovascular disease with lowering of blood sugar. A final problem is that with present treatments it is often not possible to lower the blood sugar in the majority of patients to the normal range or to the various guide line goals particularly in the younger diabetic patient who needs to protect their arteries for many more years than the elderly. This is the reason why it has been suggested that goals of blood sugar reduction in elderly type 2 diabetic patients should perhaps be less stringent. The evidence for this is scant but has led to the suggestion that treatment goals should be individualised. This is of course what all practicing physicians do in any case as we have to live with the fact that treatment for blood sugar control is far from perfect and hypoglycaemia and dietary compliance are problems that usually prevent patients from getting to target HbAlc. A recent trial was reported in the Lancet [37] the study set out to investigate whether it was possible to set and achieve individualised targets for $\mathrm{HbAlc}$ over a 24 week period in patients 70 or more years of age. Usual treatment or the addition of vildagliptin was the comparison and the results showed that the addition of vildagliptin lowered the $\mathrm{HbAlc}$ by $0.6 \%$ as compared to placebo. The question as to whether this reduction was worthwhile of course could not be answered by this study. The study did generate an editorial by Morley and Sinclair [39] in which they discuss the evidence that frailty in elderly patients may be an important reason to raise goal posts for glycaemic control. They also discuss whether a gliptin is the preferred first or second choice of pharmacological agents to lower blood sugar after diet and exercise. They conclude that the choice of use of DPP4 inhibitors should be based, in older people with diabetes, on hypoglycaemia risk and on the presence or absence of mild to moderate renal failure because of their relative safety and weight neutrality.

\section{DPP-4 Inhibitors and the Pancreas}

The potential risks of pancreatitis have been highlighted since the first report of pancreatitis in a patient on Exenatide, a GLP-1 agonist. However further report and the suggestion that in any case pancreatitis is more common in patients with diabetes have made it difficult to be sure that there is in fact an extra risk with the use of GLPI agonists or DPP-4 inhibitors [69-71]. GLP 1 receptors are found in the acinar and duct cells of the pancreas and are stimulated to proliferate by GLP 1 In 2009 acute haemorragic pancreatitis was described in a rat model of diabetes by Matveyenko et al. [72]. They also found that some rats had developed metaplasia, a pre-malignant change. The duct cell proliferation might occlude the ducts explaining the risk of pancreatitis. A case control study suggested that the risk was about 2 fold for GLP 1-based therapy resulted in a two fold increase in risk of acute pancreatitis [73]. It has been suggested there is a balance of evidence that acute pancreatitis is more common in GLP1- based therapies, and that animal studies underpin a plausible explanation. Pancreatic cancer is another worry. The finding in animal studies of premalignant pancreatic duct cells and the knowledge that GLPI can

stimulate these cells suggests that vigilance will be necessary in the future. Pancreatic cancer of course is increased in diabetes and pancreatic cancer may present with diabetes so that it may be difficult to be sure that there is indeed a risk with GLP-1 based therapies [74]. Butler et al. [75] examined the pancreata of 7 individuals treated with sitagliptin and 1 with exenetide compared with 12 individuals with type 2 diabetes treated with other agents, and 14 non-diabetics. There was an increase in the number of pre-malignant lesions and marked alpha cell hyperplasia with glucagon expressing micro adenomas and a glucagon expressing neuroendocrine tumour in one of the eight. The number of diabetics who were not on treatment with DPP4 based therapy is not sufficient, so the study should not cause alarm but the evidence for caution and vigilance in the next number of years is clear and persuasive.

\section{Thyroid Cancer}

GLP1 receptors are present on both medullary thyroid cells and papilliary cells [76]. Liraglutide was found to cause a number of C-cell tumours in the thyroid of rodents which again raised concerns. $\mathrm{C}$ cell hyperplasia is a potential precursor for medullary thyroid cancer and it is a worry that GLP1 receptors were more abundant in C-cell hyperplasia. There seems to be excess of recorded thyroid cancer on both exenitide and lyraglutide but no similar signal for the DPP4 inhibitors [77]. Sero negative polyarthropathy has been recorded with the use of DPP4 inhibitors. Three patients were described by Crickx et al. [78] and one case by Ambrosio et al. [79]. The acute arthritis is not perhaps surprising since DPP-4, also named CD 26 is expressed on many cells involved in the immune process. The symptoms appear to rapidly settle on cessation of the drug. On the positive side a GLP1 receptor agonist has been shown to alter the innate immune cells and to induce dose dependent inhibition of the invariant natural killer T cells (iNKT) cells which have been implicated in the pathogenesis of psoriasis. There is a report of a clinically significant improvement in psoriasis lesions in a patient with T2D during treatment with a GLP-1 receptor agonist in 2012 [80] and of two patients whose psoriases improved on GLP-1 analogue therapy in 2013 [81].

\section{Conclusion}

New treatments for diabetes are coming on line but prevention and 
treatment of obesity through increased exercise and reduced calorie intake still seems the best option in most patients with type 2 diabetes. Those with insulin deficiency, have new options with DPP4 inhibitors which are exciting as they demonstrate new approaches to treatment but their glucose lowering effects are modest particularly when HbAlc is near to goal [82].

\section{References}

1. Lim EL, Hollingsworth KG, Aribisala BS, Chen MJ, Mathers JC, et al. (2011) Reversal of type 2 diabetes: normalisation of beta cell function in association with decreased pancreas and liver triacylglycerol. Diabetologia 54: 2506-2514.

2. Taylor $R$ (2013) Banting Memorial lecture 2012: reversing the twin cycles of type 2 diabetes. Diabet Med 30: 267-275.

3. Yki-Järvinen H (2011) Type 2 diabetes: remission in just a week. Diabetologia 54: $2477-2479$

4. Diabetes Prevention Program Research Group (2007) The prevalence of retinopathy in impaired glucose tolerance and recent-onset diabetes in the Diabetes Prevention Program. Diabet Med 24: 137-144.

5. Cheng YJ, Gregg EW, Geiss LS, Imperatore G, Williams DE, et al. (2009) Association of $\mathrm{A} 1 \mathrm{C}$ and fasting plasma glucose levels with diabetic retinopathy prevalence in the U.S. population: Implications for diabetes diagnostic thresholds. Diabetes Care 32: 2027-2032.

6. Ford ES, Zhao G, Li C (2010) Pre-diabetes and the risk for cardiovascular disease: a systematic review of the evidence. J Am Coll Cardiol 55: 1310-1317.

7. Ziegler D, Rathmann W, Dickhaus T, Meisinger C, Mielck A; KORA Study Group (2008) Prevalence of polyneuropathy in pre-diabetes and diabetes is associated with abdominal obesity and macroangiopathy: the MONICA/KORA Augsburg Surveys S2 and S3. Diabetes Care 31: 464-469.

8. Snehalatha C, Mary S, Selvam S, Sathish Kumar CK, Shetty SB, et al. (2009) Changes in insulin secretion and insulin sensitivity in relation to the glycemic outcomes in subjects with impaired glucose tolerance in the Indian Diabetes Prevention Programme-1 (IDPP-1). Diabetes Care 32: 1796-1801.

9. Dor $\mathrm{Y}$, Glaser B (2013) $\hat{l}^{2}$-cell dedifferentiation and type 2 diabetes. N Engl J Med 368: 572-573.

10. Weng J, Li Y, Xu W, Shi L, Zhang Q, et al. (2008) Effect of intensive insulin therapy on beta-cell function and glycaemic control in patients with newly diagnosed type 2 diabetes: a multicentre randomised parallel-group trial. Lancet 371: 1753-1760.

11. Brown JC, Dryburgh JR (1971) A gastric inhibitory polypeptide. II. The complete amino acid sequence. Can J Biochem 49: 867-872.

12. Schmidt WE, Siegel EG, Creutzfeldt W (1985) Glucagon-like peptide-1 but not glucagon-like peptide-2 stimulates insulin release from isolated rat pancreatic islets. Diabetologia 28: 704-707.

13. Todd JF, Bloom SR (2007) Incretins and other peptides in the treatment of diabetes. Diabet Med 24: 223-232.

14. Eng J, Kleinman WA, Singh L, Singh G, Raufman JP (1992) Isolation and characterization of exendin-4, an exendin-3 analogue, from Heloderma suspectum venom. Further evidence for an exendin receptor on dispersed acini from guinea pig pancreas. J Biol Chem 267: 7402-7405.

15. Goke R, Fehmann HC, Linn T, Schmidt H, Krause M, et al. (1993) Exendin-4 is a high potency agonist and truncated exendin-(9-39)-amide an antagonist at the glucagon-like peptide 1-(7-36)-amide receptor of insulin-secreting betacells. J Biol Chem 268: 19650-19655

16. Kolterman OG, Kim DD, Shen L, Ruggles JA, Nielsen LL, et al. (2005) Pharmacokinetics, pharmacodynamics, and safety of exenatide in patients with type 2 diabetes mellitus. Am J Health Syst Pharm 62: 173-181.

17. Engel MF, KhemtÃ@mourian L, Kleijer CC, Meeldijk HJ, Jacobs J, et al. (2008) Membrane damage by human islet amyloid polypeptide through fibril growth at the membrane. Proc Natl Acad Sci U S A 105: 6033-6038.

18. Last NB, Rhoades E, Miranker AD (2011) Islet amyloid polypeptide demonstrates a persistent capacity to disrupt membrane integrity. Proc Nat Acad Sci U S A 108: 9460-9465.

19. Long-Smith CM, Manning S, McClean PL, Coakley MF, O'Halloran DJ, et al. (2013) The diabetes drug liraglutide ameliorates aberrant insulin receptor localisation and signalling in parallel with decreasing both amyloid- $ß$ plaque and glial pathology in a mouse model of Alzheimer's disease. Neuromolecular Med 15: 102-114.

20. Park YJ, Ao Z, Kieffer TJ, Chen H, Safikhan N, et al. (2013) The glucagonlike peptide- 1 receptor agonist exenatide restores impaired pro-islet amyloid polypeptide processing in cultured human islets: implications in type 2 diabetes and islet transplantation. Diabetologia 56: 508-519.

21. Kim W, Egan JM (2008) The role of incretins in glucose homeostasis and diabetes treatment. Pharmacol Rev 60: 470-512.

22. Van Gaal LF, Gutkin SW, Nauck MA (2008) Exploiting the antidiabetic properties of incretins to treat type 2 diabetes mellitus: glucagon-like peptide 1 receptor agonists or insulin for patients with inadequate glycemic control? Eur $\mathrm{J}$ Endocrinol 158: 773-784.

23. Kosaraju J, Murthy V, Khatwal RB, Dubala A, Chinni S, et al. (2013) Vildagliptin an anti-diabetes agent ameliorates cognitive deficits and pathology observed in streptozotocin-induced Alzheimer's disease. J Pharm Pharmacol 65: 17731784.

24. Omar BA, Vikman J, Winzell MS, Voss U, Ekblad E, et al. (2013) Enhanced beta cell function and anti-inflammatory effect after chronic treatment with the dipeptidyl peptidase-4 inhibitor vildagliptin in an advanced-aged diet-induced obesity mouse model. Diabetologia 56:1752-1760.

25. Duttaroy A, Voelker F, Merriam K, Zhang X, Ren X, et al. (2011) The DPP-4 inhibitor vildagliptin increases pancreatic beta cell mass in neonatal rats. Eur $\mathrm{J}$ Pharmacol 650: 703-707

26. Takeda Y, Fujita Y, Honjo J, Yanagimachi T, Sakagami H, et al. (2012) Reduction of both beta cell death and alpha cell proliferation by dipeptidy peptidase-4 inhibition in a streptozotocin-induced model of diabetes in mice. Diabetologia 55: 404-412.

27. Aston-Mourney K, Subramanian SL, Zraika S, Samarasekera T, Meier DT et al. (2013) One year of sitagliptin treatment protects against islet amyloidassociated $ß$-cell loss and does not induce pancreatitis or pancreatic neoplasia in mice. Am J Physiol Endocrinol Metab 305: 475-484.

28. Nabeno M, Akahoshi F, Kishida H, Miyaguchi I, Tanaka Y, et al. (2013) A comparative study of the binding modes of recently launched dipeptidy peptidase IV inhibitors in the active site. Biochem Biophys Res Commun 434 191-196.

29. Capuano A, Sportiello L, Maiorino MI, Rossi F, Giugliano D, et al. (2013) Dipeptidyl peptidase-4 inhibitors in type 2 diabetes therapy--focus on alogliptin Drug Des Devel Ther 7: 989-1001.

30. Richard KR, Shelburne JS, Kirk JK (2011) Tolerability of dipeptidyl peptidase-4 inhibitors: a review. Clin Ther 33: 1609-1629.

31. Tanaka H1, Yoshida S2, Minoura H2, Negoro K3, Shimaya A2, et al. (2014) Novel GPR40 agonist AS2575959 exhibits glucose metabolism improvement and synergistic effect with sitagliptin on insulin and incretin secretion. Life Sci 94: 115-121.

32. Gallwitz B, Rosenstock J, Rauch T, Bhattacharya S, Patel S, et al. (2012) 2-year efficacy and safety of linagliptin compared with glimepiride in patients with type 2 diabetes inadequately controlled on metformin: a randomised, double-blind, non-inferiority trial. Lancet 380: 475-483.

33. Garber AJ (2012) Hypoglycaemia: a therapeutic concern in type 2 diabetes. Lancet 379: 2215-2216.

34. Budnitz DS, Lovegrove MC, Shehab N, Richards CL (2011) Emergency hospitalizations for adverse drug events in older Americans. N Engl J Med 365: 2002-2012.

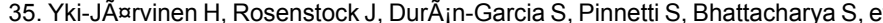
al. (2013) Effects of adding linagliptin to basal insulin regimen for inadequately controlled type 2 diabetes: a â\%o $¥ 52$-week randomized, double-blind study. Diabetes Care 36: 3875-3881.

36. Aschner P, Chan J, Owens DR, Picard S, Wang E, et al. (2012) Insulin glargine versus sitagliptin in insulin-naive patients with type 2 diabetes mellitus uncontrolled on metformin (EASIE): a multicentre, randomised open-label trial. Lancet 379: 2262-2269.

37. Strain WD, Lukashevich V, Kothny W, Hoellinger MJ, Paldánius PM. (2013) Individualised treatment targets for elderly patients with type 2 diabetes using vildagliptin add-on or lone therapy (INTERVAL): a 24 week, randomised double-blind, placebo-controlled study. Lancet 382: 409-416.

38. Barnett AH, Huisman H, Jones R, von Eynatten M, Patel S, et al. (2013) 
Linagliptin for patients aged 70 years or older with type 2 diabetes inadequately controlled with common antidiabetes treatments: a randomised, double-blind, placebo-controlled trial. Lancet 382: 1413-1423.

39. Sinclair A, Morley J (2013) Frailty and diabetes. Lancet 382: 1386-1387.

40. Morley JE, Sinclair A (2013) Individualising treatment for older people with diabetes. Lancet 382: 378-380.

41. Kirkman MS, Briscoe VJ, Clark N, Florez H, Haas LB, et al. Diabetes in older adults. (2012) Diabetes Care 35: 2650-2664.

42. Sinclair A, Morley JE, Rodriguez-Mañas L, Paolisso G, Bayer T, et al (2012) Diabetes mellitus in older people: position statement on behalf of the International Association of Gerontology and Geriatrics (IAGG), the European Diabetes Working Party for Older People (EDWPOP), and the International Task Force of Experts in Diabetes. J Am Med Dir Assoc 13: 497-502.

43. Hiatt WR, Kaul S, Smith RJ (2013) The cardiovascular safety of diabetes drugs-insights from the rosiglitazone experience. N Engl J Med 369: 1285-1287.

44. Hausenloy DJ, Whittington HJ, Wynne AM, Begum SS, Theodorou L, et al. (2013) Dipeptidyl peptidase-4 inhibitors and GLP-1 reduce myocardial infarct size in a glucose-dependent manner. Cardiovasc Diabetol 12: 154

45. Scirica BM, Bhatt DL, Braunwald E, Steg PG, Davidson J, et al. (2013) Saxagliptin and cardiovascular outcomes in patients with type 2 diabetes mellitus. N Engl J Med 369: 1317-1326.

46. White WB, Cannon CP, Heller SR, Nissen SE, Bergenstal RM, et al. (2013) Alogliptin after acute coronary syndrome in patients with type 2 diabetes. $\mathrm{N}$ Engl J Med 369: 1327-1335.

47. Gitt AK, Bramlage P, Binz C, Krekler M, Deeg E, et al. (2013) Prognostic implications of DPP-4 inhibitor vs. sulfonylurea use on top of metformin in a real world setting - results of the 1 year follow-up of the prospective DiaRegis registry. Int J Clin Pract 67: 1005-1014.

48. Karagiannis T, Paschos P, Paletas K, Matthews DR, Tsapas A (2012) Dipeptidyl peptidase- 4 inhibitors for treatment of type 2 diabetes mellitus in the clinical setting: systematic review and meta-analysis. BMJ 344: e1369.

49. Nystrom T, Gutniak MK, Zhang Q, Zhang F, Holst JJ, et al. (2004) Effects of glucagon-like peptide- 1 on endothelial function in type 2 diabetes patients with stable coronary artery disease. Am J Physiol Endocrinol Metab 287: E12091215.

50. Luptak I, Yan J, Cui L, Jain M, Liao R, et al. (2007) Long-term effects of increased glucose entry on mouse hearts during normal aging and ischemic stress. Circulation 116: 901-909.

51. Nikolaidis LA, Elahi D, Shen YT, Shannon RP (2005) Active metabolite of GLP-1 mediates myocardial glucose uptake and improves left ventricular performance in conscious dogs with dilated cardiomyopathy. Am J Physio Heart Circ Physiol 289: 2401-2408

52. Nikolaidis LA, Mankad S, Sokos GG, Miske G, Shah A, et al. (2004) Effects of glucagon-like peptide- 1 in patients with acute myocardial infarction and left ventricular dysfunction after successful reperfusion. Circulation 109: 962-965.

53. Zhao T, Parikh P, Bhashyam S, Bolukoglu H, Poornima I, et al. (2006) Direct effects of glucagon-like peptide-1 on myocardial contractility and glucose uptake in normal and postischemic isolated rat hearts. J Pharmacol Exp Ther 317: 1106-1113.

54. Ban K, Noyan-Ashraf MH, Hoefer J, Bolz SS, Drucker DJ, et al. (2008) Cardioprotective and vasodilatory actions of glucagon-like peptide 1 receptor are mediated through both glucagon-like peptide 1 receptor-dependent and -independent pathways. Circulation 117: 2340-2350.

55. Rahmi RM, Uchida AH, Rezende PC, Lima EG, Garzillo CL, et al. (2013) Effect of hypoglycemic agents on ischemic preconditioning in patients with type 2 diabetes and symptomatic coronary artery disease. Diabetes Care 36: 16541659 .

56. Kim SJ, Nian C, McIntosh CH (2010) Sitagliptin (MK0431) inhibition of dipeptidyl peptidase IV decreases nonobese diabetic mouse CD4+ T-cell migration through incretin-dependent and -independent pathways. Diabetes 59: $1739-1750$

57. Arakawa M, Mita T, Azuma K, Ebato C, Goto H, et al. (2010) Inhibition of monocyte adhesion to endothelial cells and attenuation of atherosclerotic lesion by a glucagon-like peptide- 1 receptor agonist, exendin-4. Diabetes 59 : 1030-1037.

58. Dai Y, Wang X, Ding Z, Dai D, Mehta JL (2013) DPP-4 inhibitors repress foam cell formation by inhibiting scavenger receptors through protein kinase $\mathrm{C}$ pathway. Acta Diabetol.

59. Burgmaier M, Heinrich C, Marx N (2013) Cardiovascular effects of GLP-1 and GLP-1-based therapies: implications for the cardiovascular continuum in diabetes? Diabet Med 30: 289-299.

60. Scott R, Wu M, Sanchez M, Stein P (2007) Efficacy and tolerability of the dipeptidyl peptidase-4 inhibitor sitagliptin as monotherapy over 12 weeks in patients with type 2 diabetes. Int J Clin Pract 61: 171-180.

61. Matikainen N, MÃanttÃari S, Schweizer A, Ulvestad A, Mills D, et al. (2006) Vildagliptin therapy reduces postprandial intestinal triglyceride-rich lipoprotein particles in patients with type 2 diabetes. Diabetologia 49: 2049-2057.

62. Nordestgaard BG, Benn M, Schnohr P, Tybjaerg-Hansen A (2007) Non- fasting triglycerides and risk of myocardial infarction, ischemic heart disease, and death in men and women. JAMA 298: 299-308.

63. Zaruba MM, Theiss HD, Vallaster M, Mehl U, Brunner S, et al. (2009) Synergy between CD26/DPP-IV inhibition and G-CSF improves cardiac function after acute myocardial infarction. Cell Stem Cell 4: 313-323.

64. Theiss HD, Brenner C, Engelmann MG, Zaruba MM, Huber B, et al. (2010) Safety and efficacy of SITAgliptin plus GRanulocyte-colony-stimulating factor in patients suffering from Acute Myocardial Infarction (SITAGRAMI-Trial)-rationale, design and first interim analysis. Int J Cardiol 145: 282-284

65. Matsubara J, Sugiyama S, Akiyama E, Iwashita S, Kurokawa H, et al (2013) Dipeptidyl peptidase-4 inhibitor, sitagliptin, improves endothelial dysfunction in association with its anti-inflammatory effects in patients with coronary artery disease and uncontrolled diabetes. Circ J $77:$ 1337-1344.

66. Hocher B, Oberth $\tilde{A}^{1 / 4} / \mathrm{r}$ D, Slowinski T, Querfeld U, Schaefer F, et al. (2013) Modeling of oxidized PTH (oxPTH) and non-oxidized PTH (n-oxPTH) recepto binding and relationship of oxidized to non-oxidized PTH in children with chronic renal failure, adult patients on hemodialysis and kidney transplant recipients. Kidney Blood Press Res 37: 240-251.

67. Liu WJ, Xie SH, Liu YN, Kim W, Jin HY, et al. (2012) Dipeptidyl peptidase IV inhibitor attenuates kidney injury in streptozotocin-induced diabetic rats. J Pharmacol Exp Ther 340: 248-255.

68. Fujita H, Taniai H, Murayama $H$, Ohshiro $H$, Hayashi $H$, et al. (2013) DPP 4 inhibition with alogliptin on top of angiotensin II type 1 receptor blockade ameliorates albuminuria via up-regulation of SDF-1a in type 2 diabetic patients with incipient nephropathy. Endocr J.

69. Dore DD, Bloomgren GL, Wenten M, Hoffman C, Clifford CR, et al. (2011) A cohort study of acute pancreatitis in relation to exenatide use. Diabetes Obes Metab 13: 559-566.

70. Dore DD, Seeger JD, Arnold Chan K (2009) Use of a claims-based active drug safety surveillance system to assess the risk of acute pancreatitis with exenatide or sitagliptin compared to metformin or glyburide. Curr Med Res Opin 25: 1019-1027

71. Girman CJ, Kou TD, Cai B, Alexander CM, O'Neill EA, et al. (2010) Patients with type 2 diabetes mellitus have higher risk for acute pancreatitis compared with those without diabetes. Diabetes Obes Metab 12: 766-771.

72. Matveyenko AV, Dry S, Cox HI, Moshtaghian A, Gurlo T, et al. (2009) Beneficial endocrine but adverse exocrine effects of sitagliptin in the human islet amyloid polypeptide transgenic rat model of type 2 diabetes: interactions with metformin Diabetes 58: 1604-1615.

73. Singh S, Chang HY, Richards TM, Weiner JP, Clark JM, et al. (2013) Glucagonlike peptide 1-based therapies and risk of hospitalization for acute pancreatitis in type 2 diabetes mellitus: a population-based matched casecontrol study. JAMA Intern Med 173: 534-539.

74. Butler PC, Elashoff M, Elashoff R, Gale EA (2013) A critical analysis of the clinical use of incretin-based therapies: Are the GLP-1 therapies safe? Diabetes Care 36: 2118-2125

75. Butler AE, Campbell-Thompson M, Gurlo T, Dawson DW, Atkinson M, et a (2013) Marked expansion of exocrine and endocrine pancreas with incretin therapy in humans with increased exocrine pancreas dysplasia and the potential for glucagon-producing neuroendocrine tumors. Diabetes 62: 25952604

76. Gier B, Butler PC, Lai CK, Kirakossian D, DeNicola MM, et al. (2012) Glucagon like peptide-1 receptor expression in the human thyroid gland. J Clin Endocrinol Metab 97: 121-131. 
Citation: Tomkin GH (2014) Treatments for Type 2 Diabetes; a Focus on DPP4 Inhibitors. Pharmaceut Reg Affairs 3: 114. doi:10.4172/21677689.1000114

77. Elashoff M, Matveyenko AV, Gier B, Elashoff R, Butler PC (2011) Pancreatitis, pancreatic, and thyroid cancer with glucagon-like peptide-1-based therapies. Gastroenterology 141: 150-156

78. Crickx E, Marroun I, Veyrie C, Le Beller C, Schoindre Y, et al. (2013) DPP4 inhibitor-induced polyarthritis: a report of three cases. Rheumatol Int.

79. Ambrosio ML, Monami M, Sati L, Marchionni N, Di Bari M, et al. (2013) GLP-1 receptor agonist-induced polyarthritis: a case report. Acta Diabetol.

80. Buysschaert M, Tennstedt D, Preumont V (2012) Improvement of psoriasis during exenatide treatment in a patient with diabetes. Diabetes Metab 38: 8688.
81. Hogan AE, Tobin AM, Ahern AM, Corrigan, MA, Gaoatswe G, et al. (2011) Glucagon-like peptide-1 (GLP-1) and the regulation of human invariant natural killer T cells: lessons from obesity, diabetes and psoriasis. Diabetologia 54 2745-2754.

82. Esposito K, Chiodini P, Capuano A, Maiorino MI, Bellastella G, et al. (2013) Baseline glycemic parameters predict the hemoglobin A1c response to DPP 4 inhibitors : Meta-regression analysis of 78 randomized controlled trials with 20,053 patients. Endocrine. 